\title{
Correction to: Optimized THP-1 differentiation is required for the detection of responses to weak stimuli
}

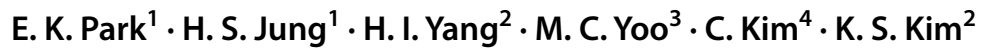

Published online: 12 September 2020

C) Springer Nature Switzerland AG 2020

\section{Correction to: Inflamm. Res. 56 (2007) 45-50 https://doi.org/10.1007/s00011-007-6115-5}

After the publication of the original article we were made aware that in Fig. 2d the images for PMA $2.5 \mathrm{ng} / \mathrm{ml}$ and PMA $25 \mathrm{ng} / \mathrm{ml}$ are identical. Figure 2d PMA $25 \mathrm{ng} / \mathrm{ml}$ is an accidental duplicate and should be disregarded. This error is due to a mistake at submission stage. We would like apologize for not being able to provide the correct image due to the time that has passed since submission and for any confusion caused to readers. However, this correction will in no way affect the substance, the validity of the results, nor would it undermine the conclusions.
Publisher's Note Springer Nature remains neutral with regard to jurisdictional claims in published maps and institutional affiliations.

The original article can be found online at https://doi.org/10.1007/ s00011-007-6115-5.

K. S. Kim

labrea46@yahoo.co.kr

1 East-West Bone and Joint Research Center, College of Medicine, Kyung Hee University, Seoul, South Korea

2 Department of Internal Medicine, East-West Bone and Joint Research Center, College of Medicine, Kyung Hee University, Seoul, South Korea

3 Department of Orthopedic Surgery, College of Medicine, Kyung Hee University, Seoul, South Korea

4 Center for Advanced Medical Education By BK21 Project, Inha University School of Medicine, Incheon, South Korea 